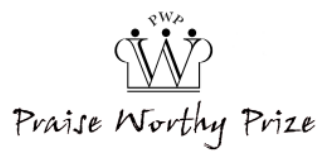

\title{
Laminar-Turbulent Transition on a Cambered NACA 16-009 Airfoil at Low Speed
}

\author{
Benoît G. Marinus, Jan Vercauteren, Robin Vandenberghe, Julie Smeulders
}

\begin{abstract}
Infrared thermography, force measurements, and oil flow visualizations are used to investigate the flow patterns around a cambered NACA16-409 airfoil at low Mach number. This cambered profile is widely used for propellers despite the lack of knowledge concerning its flow characteristics. The post-processing of thermograms relies on the analysis of the surface temperature gradient and identification of inflexion points in the temperature distribution. The observations made on the thermograms, based on the distribution of the temperature and Stanton number, are substantiated by the oil flow visualizations. RANS simulations with a transitional SST $k-\omega \& \gamma$ turbulence model corroborate the analysis and deliver detailed insight in the flow around the airfoil. Depending on the angle of attack, three distinct flow patterns have been identified: laminar flow with early separation, laminar separation bubble with trailing edge separation, and turbulent flow with trailing edge separation. The shift between the last two regimes occurs sharply. The prediction capability of the transitional RANS simulations and XFOIL in terms of separation as well as reattachment location are compared with the experimental results. The force-coefficients dependency on the angle-of-attack, obtained by experiments, XFOIL, and RANS simulations, bear the traces from these flow patterns. Copyright (C) 2020 The Authors.

Published by Praise Worthy Prize S.r.l.. This article is open access published under the CC BY-NC-ND license (http://creativecommons.org/licenses/by-nc-nd/3.0/).
\end{abstract}

Keywords: Boundary Layer, Laminar-Turbulent Transition, Separation, Laminar Separation Bubble, Thermography, NACA16-Series

\section{Nomenclature}

Heat capacity $[\mathrm{J} / \mathrm{kg} / \mathrm{K}]$

Drag coefficient

Local skin friction coefficient

Lift coefficient

Design lift coefficient

Pressure coefficient

Chord [m]

Isobar heat capacity $[\mathrm{J} / \mathrm{kg} / \mathrm{K}]$

Approximate relative error

Extrapolated relative error

Force component [N]

Convective heat transfer coefficient

$\left[\mathrm{W} / \mathrm{m}^{2} / \mathrm{K}\right]$

Heat conductivity $[\mathrm{W} / \mathrm{m} / \mathrm{K}]$

Interpolation coefficient

Separation length [m]

Mach number

Prandtl number

Convective heat flux $\left[\mathrm{W} / \mathrm{m}^{2}\right]$

Reynolds number based on chord

Reynolds number based on transitional momentum thickness

Stanton number

Temperature [K]

Channel Voltage [V]

$\begin{array}{ll}V & \text { Velocity }[\mathrm{m} / \mathrm{s}] \\ x & \text { Coordinate } \\ \alpha & \text { Angle of attack }\left[{ }^{\circ}\right] \\ \varepsilon & \text { Emissivity } \\ \rho & \text { Mass density }\left[\mathrm{kg} / \mathrm{m}^{3}\right] \\ \infty & \text { Freestream value } \\ r & \text { Recovery value } \\ w & \text { Wall value } \\ \sim & \text { Non-dimensionalized value } \\ \text { CFD } & \text { Computational Fluid Dynamics } \\ \text { GCI } & \text { Grid Convergence Index } \\ \text { IR } & \text { InfraRed } \\ \text { NACA } & \text { National Advisory Committee for } \\ & \text { Aeronautics } \\ \text { LSB } & \text { Laminar Separation Bubble } \\ \text { RANS } & \text { Reynolds-Averaged Navier-Stokes } \\ \text { TE } & \text { Trailing Edge }\end{array}$

\section{Introduction}

The NACA 16-series has been specifically designed for use in aircraft propeller blades. Hence, it is widely found in propeller designs as in [1]-[9]. The NACA 16series features flat pressure distributions intended to delay the onset of drag rise due to compressibility issues, and a small leading-edge radius. Both features result in high lift to drag ratios at low angle of attack in cruise 
[10] but also suffer from a reduction in efficiency at high angle of attack due to the separation triggered by the sharp leading edge [1]. Therefore, the investigation of the low-Mach operating conditions, typical of takeoff/landing and the initial climb segment, is important.

Yet, to the authors' knowledge, studies on this particular profile are limited to the aerodynamic performance [11], [12], the data collected in [1], the validation results in [2], which are more than three decades old, and the roughness-induced transition study in the transonic regime for a symmetric NACA 16-series airfoil in [24]. In the study of the flow around immersed bodies such as airfoils, the knowledge of the actual laminar/turbulent/separated state of the boundary layer is of high importance given its implications on the performance and behavior of the body under scrutiny [13]-[15].

The change in skin friction associated with transition or separation results in a change in surface heat transfer [13]. Therefore, infrared thermography as a means of characterizing the status of the boundary layer, has become a popular technique because of its ease of use and its non-intrusiveness [15]-[36]. However, this technique alone is not sufficient to discriminate between some states. A detailed discussion of the basic principles and measurement errors can be found in [34], [35].

Recent developments reported on: (1) the importance of the heating technique, especially when external heating is applied [17], [23], [25], [27], [28]; (2) on the issues selecting the appropriate material for the body [23], [28]-[31], either for the bulk body [28, [29], [31], or by applying a paint or a coating to circumvent the properties of the core at the surface where heat exchanges occur [23], [28]-[30]; (3) and on the choice of a post-processing technique to infer quantitative results.

These techniques range from simple contrast-based algorithms to differential analysis of a sequence of images in space [16], [18]-[20], [26], [33] or time [25].

The present work intends to combine infrared thermography, force measurements, and oil flow visualizations to investigate the flow patterns around a cambered NACA16-409 airfoil $\left(C_{l d}=0.3675\right)$ at low Mach number $\left(\mathrm{Ma}=0.1, \operatorname{Re}_{c}=330,000\right)$. First, the experimental set-up for the investigation by infrared thermography is described before explaining the consolidating experiments (forces measurements and oil flow visualization). The RANS model is then depicted.

All measurements are then consolidated in the next section before drawing conclusions.

\section{Experimental Setup and Theory}

\section{II.1. Measurement Principle}

The convective heat transfer rate $\dot{q}_{c o n v}$ is given by Newton's cooling law:

$$
\dot{q}_{c o n v}=h\left(T_{w}-T_{r}\right)
$$

where $h$ is the convective heat transfer coefficient, $T_{w}$ is the wall temperature and $T_{r}$ is the recovery temperature of the flow ( $T_{r}=T_{\infty}$ for low subsonic flows). With $\rho_{\infty}$ the mass density, $\mathrm{V}$ the velocity, and $c_{p}$ the isobar heat capacity, the Stanton number relates the heat transferred into a fluid to its thermal capacity:

$$
S t=\frac{h}{\rho_{\infty} V c_{p}}
$$

For subsonic air flow (for which the Prandtl number is $\operatorname{Pr} \approx 1$ ), the heat and momentum transfer in the boundary layer are related through Reynold's analogy:

$$
S t \approx \frac{C_{f}}{2}
$$

Consequently, the skin friction coefficient and heat transfer rate are directly related through the convective heat transfer coefficient so that an increase in the turbulent behavior of the boundary layer results in an increased heat transfer, thence a lower wall temperature.

\section{II.2. Measurement Setup}

The IR radiation emitted from the wing profile is measured with a FLUKE Ti50 camera equipped with a vanadium oxide uncooled sensor. The camera operates in the $8 \mu \mathrm{m}$ to $14 \mu \mathrm{m}$ spectral band with a Noise Equivalent Temperature Difference (NETD) of $\leq 70 \mathrm{mK}$ at $30{ }^{\circ} \mathrm{C}$ and has a resolution of $320 \times 240$. Since knowledge of the absolute temperature $T$ is not required to gather the information on the laminar/turbulent/separated behavior of the boundary layer, temperature profiles are nondimensionalized with respect to the minimum and maximum temperature of the thermogram at hand:

$$
\tilde{T}=\frac{T-T_{\min }}{T_{\max }-T_{\min }}
$$

In several recent contributions, the external heating is provided by a single source [17], [25], [27]-[28] with difficulties resulting from the non-uniform heating [27], [29]. In the present setup, an array of spots is used for external heating of the wing profile prior to the measurements (Fig. 1).

The array consists of HOENLE Superspot 575 solar simulation spots that are arranged to yield a uniformly distributed $800 \mathrm{~W} / \mathrm{m}^{2}$ irradiance (according to [37]) over a given surface [38].

\section{II.3. Wing Profile}

A cambered version of the NACA 16-009 airfoil with $C_{l d}=0.3675$ is used since it is representative for the blade section at $75 \%$-radius of several propeller families.

The profile is milled from OBOMODULAN boards made of high-density polyurethane foam (PUR). For the present tests, boards of $300 \mathrm{~kg} / \mathrm{m}^{3}$ are used while densities of up to $1600 \mathrm{~kg} / \mathrm{m}^{3}$ can be reached if required. 


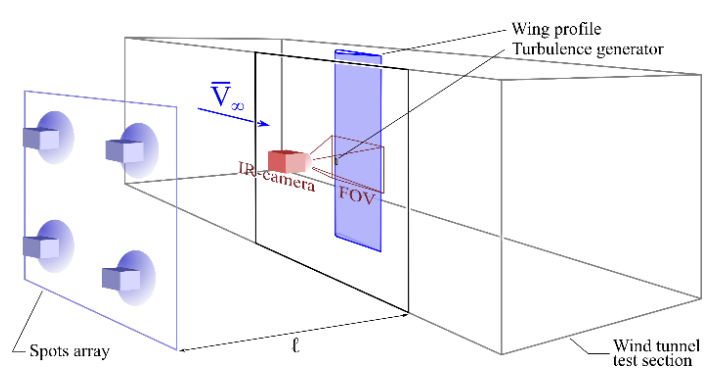

Fig. 1 Experimental set-up showing the wing profile with turbulence generator, the IR-camera and its Field Of View (FOV), and the array of spots used in the heating phase

Such high-density boards can be machined to parts with a homogeneous and smooth surface while having sufficient mechanical properties for wind-tunnel testing.

The thermal properties of high-density PUR are summarized in Table I. Although not reported in [29], [31], high-density polyurethane foam is a suitable candidate for infrared thermography, especially in the $300 \mathrm{~kg} / \mathrm{m}^{3}$ range, because of its low specific heat capacity $C$ and heat conductivity $k$, while having a homogeneous structure. Its high emissivity $\varepsilon$ alleviates the issue of infrared reflections [23], [30]. In accordance with established practice [27], [28], [39], the wing profile is equipped with a turbulence generator at the leading edge (Fig. 1) in order to provide the disturbed (turbulent) flow as a witness.

\section{II.4. Process}

The experiment starts with the heating phase in which external heating is provided by the array of spots (Fig. 1).

Fig. 2 shows the temperature distribution over the profile's surface obtained with the present arrangement.

The temperature variation over the main surface of interest after the heating phase is of the order of $0.5 \mathrm{~K}$.

The high emissivity of polyurethane foam and the granularity of the surface in terms of IR or visible wavelengths, yield a non-reflecting surface in the infrared range thereby circumventing known issues with other materials [25], [30]. Then, the tunnel wall, which features an access window for the IR-camera, is put in place before measurements are taken once the desired operating Mach number is reached. The measurements can typically be sustained for 10 minutes. The temperature difference between the undisturbed flow of interest and the disturbed flow during the measurement phase is higher than $0.8 \mathrm{~K}$.

All infrared measurements are performed in the closed section of the low-turbulence ( $\mathrm{Tu} \leq 0.07 \%$ ) wind-tunnel for a Mach number (Ma) of 0.1 and a Reynolds number based on the chord $\left(\operatorname{Re}_{c}\right)$ of 330,000 .

TABLE I

TyPiCAl MATERIAL Properties OF High-DENSITY POLYURETHANE FOAMS

\begin{tabular}{cccc}
\hline \hline$\rho\left(\mathrm{kg} / \mathrm{m}^{3}\right)$ & $C(\mathrm{~J} / \mathrm{kg} / \mathrm{K})$ & $k(\mathrm{~W} / \mathrm{m} / \mathrm{K})$ & $\varepsilon$ \\
\hline 300 & 1120 & 0.05 & 0.9 \\
500 & $1400-1500$ & $0.05-0.075$ & \\
1600 & $2000-2100$ & $0.12-0.17$ & \\
\hline \hline
\end{tabular}

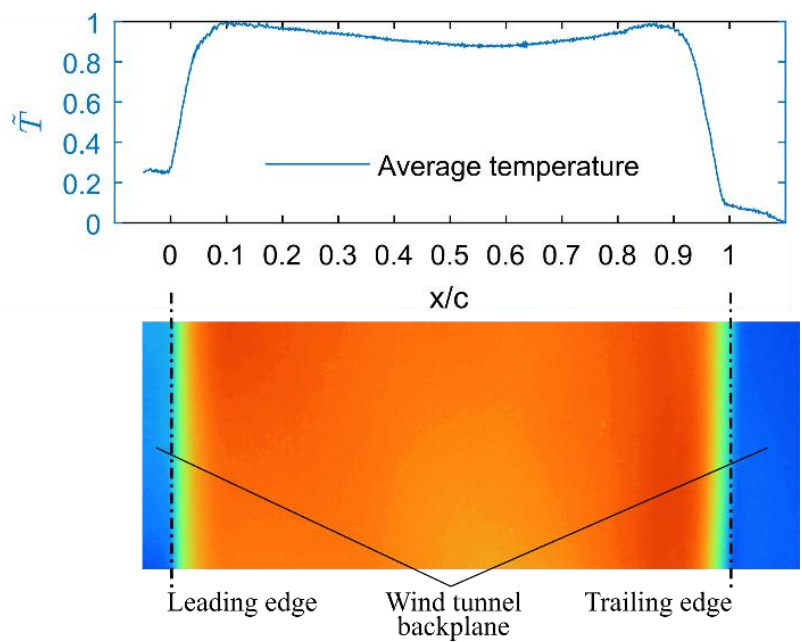

Fig. 2. Average non-dimensionalized temperature profile $(\tilde{T})$ on the wing profile and corresponding thermogram measured at the end of the heating phase

\section{Consolidating Experiments}

\section{III.1. Force Measurements}

Force measurements were made in identical flow conditions with an in-house designed and built threecomponent balance shown in Fig. 3. Independent measurement of the lift, drag, and pitching moment with negligible interactions is obtained thanks to pivot-rods (shown in purple and yellow in Fig. 3) that free one single degree of freedom at a time. It uses three Futek LSM400 load cells and IAA300 amplifiers. The BoxBehnken calibration scheme has 18 points and yields the coefficients of the polynomial with interaction terms:

$$
\begin{gathered}
F_{i}=k_{i 0}+k_{i 1} U_{1}+k_{i 2} U_{2}+k_{i 3} U_{3}+ \\
+k_{i 12} U_{1} U_{2}+k_{i 13} U_{1} U_{3}+k_{i 23} U_{2} U_{3}(i=1,2,3)
\end{gathered}
$$

that define the response surface between the known forces $F_{i}$ and the measured load cell output voltages $U_{i}$.

The measurement accuracy is of $1.5 \%$ for lift and $4.6 \%$ for drag.

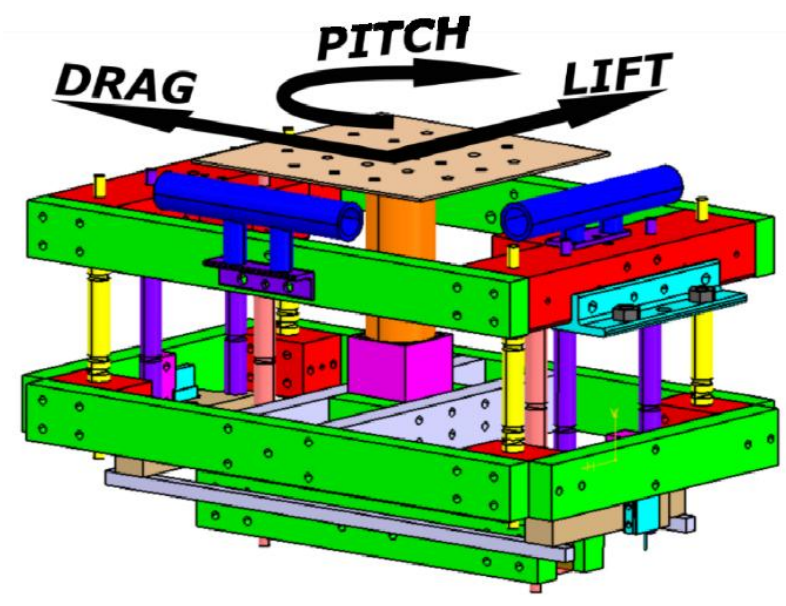

Fig. 3. In-house designed and built 3-components balance 


\section{III.2. Oil Flow Visualizations}

The oil flow visualizations are performed under flow conditions identical to the infrared ones but in an open test-section wind-tunnel. Optical pictures have been taken after sufficient running time for the proprietary oils and pigments mixture to dry.

\section{Numerical Simulations}

\section{IV.1. Spatial Discretization}

The reference $\mathrm{C}$-grid consists of $399 \times 336$ points respectively on the airfoil surface and in the wall-normal direction. It has an average $\mathrm{y}+$-value of 0.21 on the airfoil surface. Angle-of-attack corrections according to [40] are applied for matching operating conditions but never exceed $0.3^{\circ}$.

A grid convergence study has been completed according to Celik et al. [41] with a $285 \times 240$ coarse grid and a $559 \times 470$ fine grid. The drag coefficient $C_{D}$ and non-dimensionalized point of separation location $l_{\text {sep }} / c$ at $3^{\circ}$ angle of attack are considered as indicators. The indicators from Table II as well as the errors and the Grid Convergence Index (GCI) from Table III suggest that satisfactory grid independence is achieved.

\section{IV.2. Numerical Model}

Numerical simulations and oil flow experiments consolidate the observations made on the basis of the thermal images. The 2D steady- RANS simulations of the undisturbed flow around the airfoil in free-field are performed with the transitional SST k- $\omega$ and $\gamma$ turbulence model of ANSYS Fluent which couples the shear-stress transport k- $\omega$ model developed by Menter [43] with a single transport equation for the intermittency $\gamma$ and transition momentum thickness Reynolds number [44], [45]. The model has provisions for separation-induced transition ensuring rapid transition once laminar separation occurs. Constant-temperature no-slip wall conditions are applied for the airfoil as a model for the temperature profile measured at the start of the experiment whereas far-field conditions apply on the exterior boundaries.

TABLE II

GRID INDEPENDENCE GENERAL RESULTS ( $\mathrm{J}=1.61)$

\begin{tabular}{ccccc}
\hline \hline & Experiments & Fine & Regular & Coarse \\
\hline$C_{D}$ & 0.0089 & 0.0086 & 0.0086 & 0.0088 \\
$l_{\text {sep }} / c$ & 0.74 & 0.7265 & 0.7261 & 0.7273 \\
\hline \hline
\end{tabular}

TABLE III

GRID INDEPENDENCE INDICATORS ACCORDING TO CELIK ET AL. [41]

\begin{tabular}{cccc}
\hline \hline & & Fine-Regular & Regular-Coarse \\
\hline \multirow{3}{*}{$C_{D}$} & $e_{a}(\%)$ & 0.22 & 2.47 \\
& $e_{\text {ext }}(\%)$ & 0.02 & 2.40 \\
& $\mathrm{GCI}(\%)$ & 0.02 & 0.29 \\
\multirow{4}{*}{$l_{\text {sep }} / c$} & $e_{a}(\%)$ & 0.06 & 0.16 \\
& $e_{\text {ext }}(\%)$ & 0.03 & 0.09 \\
& $\mathrm{GCI}(\%)$ & 0.04 & 0.16 \\
\hline \hline
\end{tabular}

The mass and energy conservation equations and the transport equations are solved using second-order schemes.

\section{Measurements and Post-Processing}

The combined results from infrared thermography, oil flow visualizations, and CFD are shown in Figs. 4-6 respectively for angles of attack of $0^{\circ}, 3^{\circ}$, and $9^{\circ}$. Each of these angles illustrates the distinctive flow patterns shown in Fig. 7.

Since the chordwise surface temperature gradient is indicative of the state of the boundary layer [30], [34], we have used the second derivative of the temperature distribution to identify the presence of significant above measurement noise inflexion points which are related to events in the aerodynamic behavior of the boundary layer [20], [23], [24], [35].

For this purpose, a low-pass filter is applied to get rid of spurious inflexion points related to measurement-noise as in [23].

The inflexion points are shown in Figs. 4-6 and denote major events occurring in the boundary layer. The advantage of the inflexion-point method over differential methods is that it does not require a noticeable change in event location between two flow conditions [18], [26].

Indeed, the flow pattern of Figs. 4 for example is maintained between $0^{\circ}$ and $3^{\circ}$ angle-of-attack. The thermogram at $0^{\circ}$ angle-of-attack is shown in Figs. 4 together with the non-dimensionalized temperature profile, the oil-flow visualization, as well as the pressure and skin-friction coefficients, Stanton number profile, and chordwise velocity contours issued from the numerical simulations.

The rows of pixels used in the spanwise averaging process, which constitutes a first low-pass filter [35], and the distinctive flow features are also highlighted. Because of Eq. (3), the decreasing skin friction from the leading edge to $75 \%$-chord goes in pair with a decrease in heat transfer from the hot surface resulting in an increase of the surface temperature and consequently of the intensity in the thermogram.

This is also evidenced by the difference in surface temperature gradient between the undisturbed and the disturbed turbulent flow. At 73\%-chord for the experiments (first inflexion point in $\tilde{T}$ ) and $76 \%$-chord for the CFD, the boundary layer separates.

The low speed flow along the wall in the separated region heats up leading to high wall-temperatures, thence a small temperature gradient in the wall normal direction that thwarts convective heat transfer with a consequent drop in Stanton number.

Close to $85 \%$-chord, the second inflexion point in $\tilde{T}$ marks where the separated shear flow becomes turbulent.

The location of transition for the CFD results shown in Fig. 7 is educed from the empirical correlation on the transitional momentum thickness Reynolds number $\operatorname{Re}_{\theta, t}$ in [46], which are similar to Abu-Ghannam and Shaw [47]. 
a)

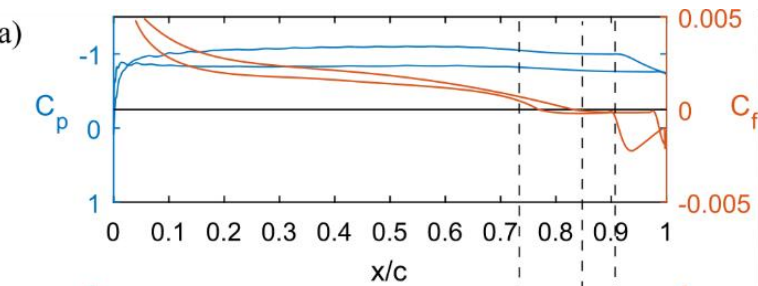

b)

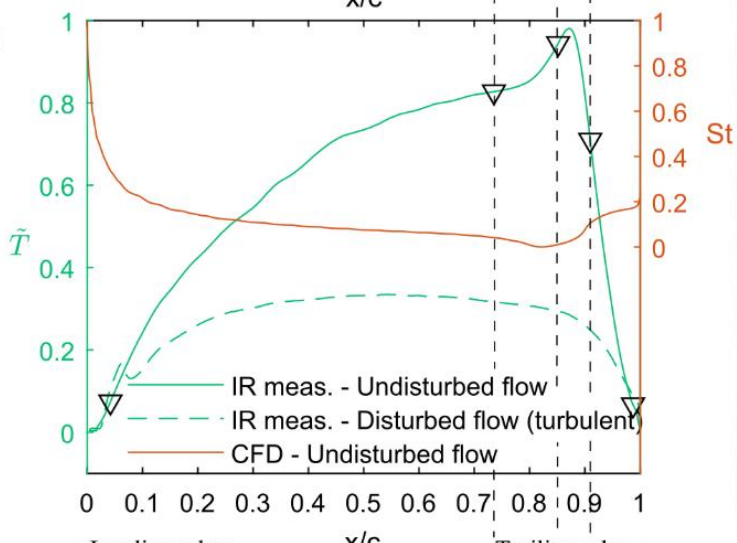

c)

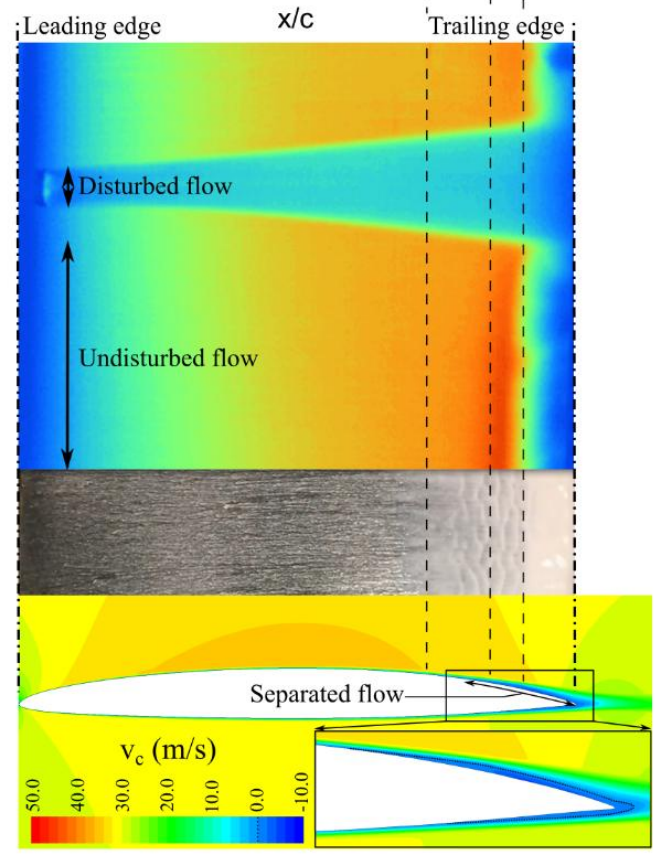

Figs. 4. Results at $0^{\circ}$ angle of attack (suction side): a) pressure and skin friction coefficients from CFD $\left(C_{p}\right.$ and $\left.C_{f}\right)$; b) non-dimensionalized temperature profile $\tilde{T}$ from IR-thermography with emphasis on the inflection points $(\nabla)$, and Stanton number distribution from CFD (St); c) thermogram with indication of the rows used for spanwise averaging ( $\rightarrow$ ) of the undisturbed and disturbed (turbulent) flows; d) oil flow visualization; e) chordwise velocity contours from CFD

Downstream of this point, the Stanton-profile features higher heat transfer to the fluid. The turbulent flow does not reattach as is evidenced from the skin-friction profile, the oil-flow visualization, and velocity profiles.

However, the non-reattachment cannot be deduced from the thermogram which features an additional inflexion point where the temperature profile matches that of the disturbed turbulent witness-flow. This third inflexion point corresponds to increased skin friction in the reversed wall-bounded flow and transfer of additional heat. a)

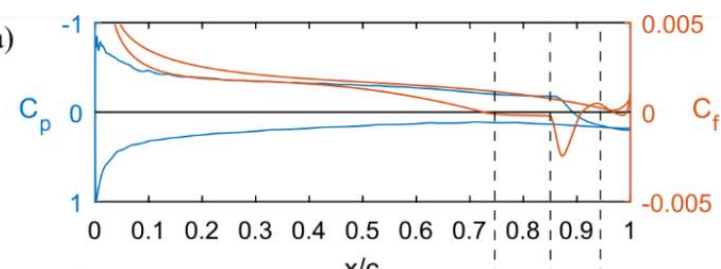

b)

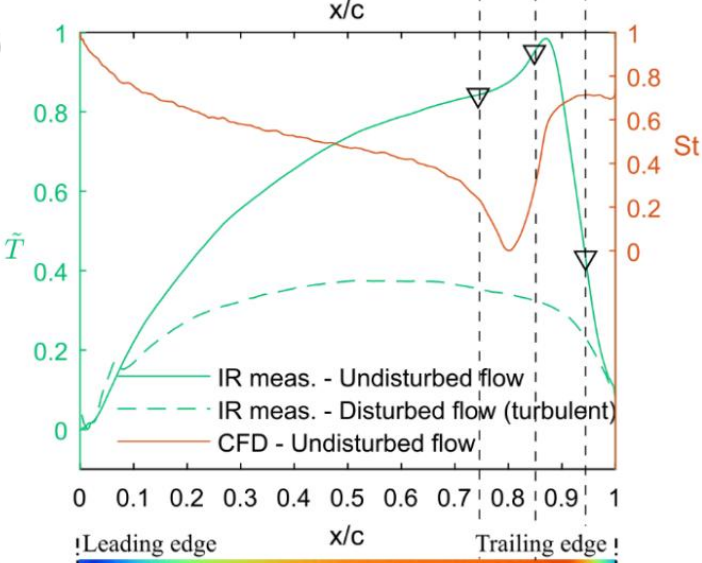

c)

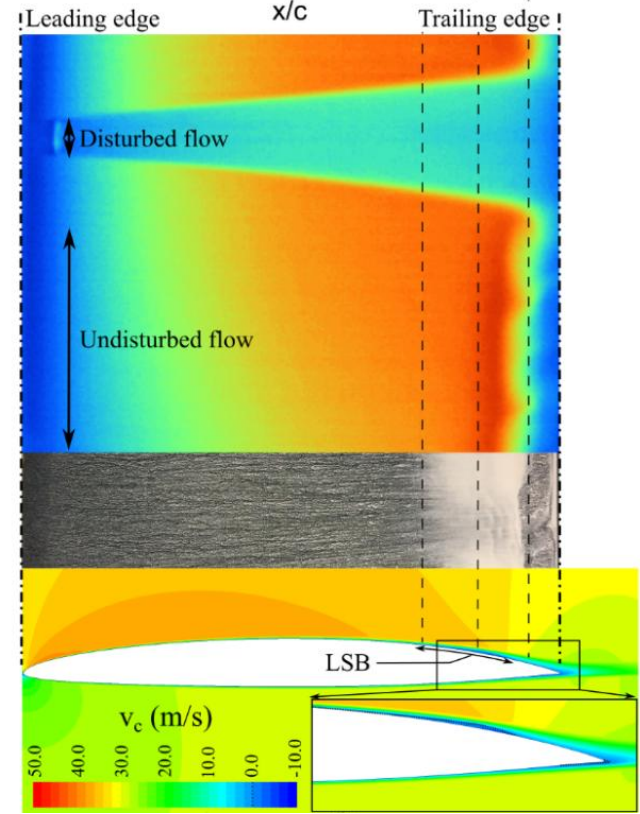

Figs. 5. Results at $3^{\circ}$ angle of attack (suction side): a) pressure and skin friction coefficients from CFD $\left(C_{p}\right.$ and $\left.C_{f}\right)$; b) non-dimensionalized temperature profile $\tilde{T}$ from IR-thermography with emphasis on the inflection points $(\nabla)$, and Stanton number distribution from CFD $(\mathrm{St})$; c) thermogram with indication of the rows used for spanwise averaging ( $\longrightarrow$ ) of the undisturbed and disturbed (turbulent) flows; d) oil flow visualization; e) chordwise velocity contours from CFD

Figs. 5 illustrate the flow pattern found when a Laminar Separation Bubble (LSB) occurs, here for $3^{\circ}$ angle-of-attack. The laminar boundary layer separates at 74\%-chord (first inflexion point in $\widetilde{T}$ ) with a $1 \%$ discrepancy with the CFD. At 85\%-chord, the separated shear flow becomes turbulent (second inflexion point in $\tilde{T}$ ) within 2\%-chord of the CFD prediction. The resulting increased momentum exchange in the direction perpendicular to the wall results in higher skin friction in the separated bubble and the fluid adjacent to the wall is more effectively heated when compared to the Stantondistribution from Fig. 4(b). 
a)

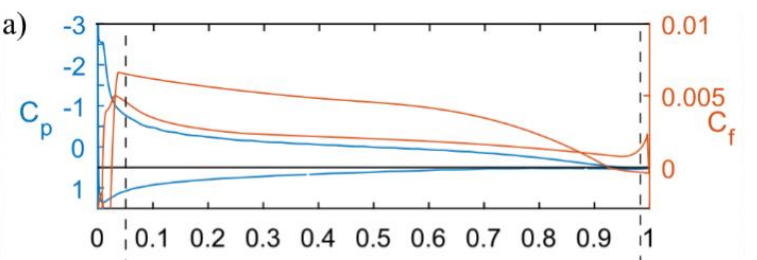

b)

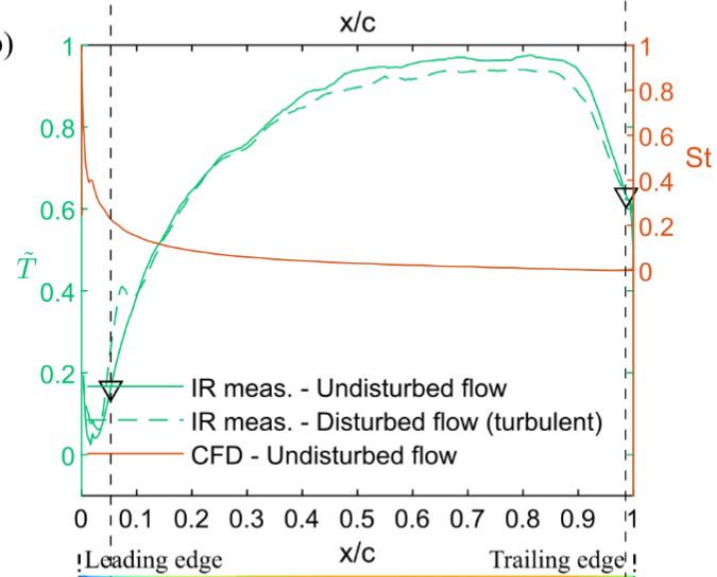

c)

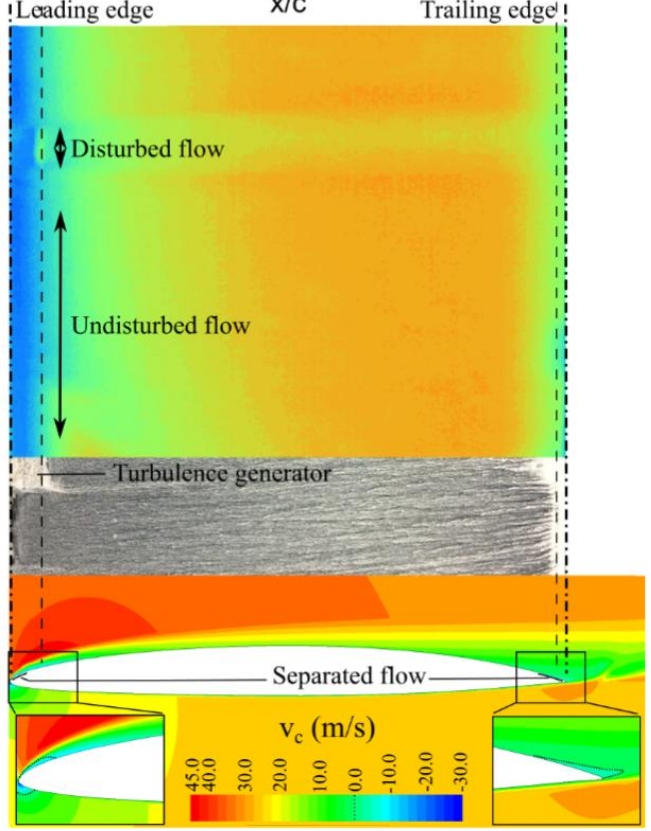

Figs. 6. Results at $9^{\circ}$ angle of attack (suction side): a) pressure and skin friction coefficients from CFD $\left(C_{p}\right.$ and $\left.C_{f}\right)$; b) non-dimensionalized temperature profile $\widetilde{T}$ from IR-thermography with emphasis on the inflection points $(\nabla)$, and Stanton number distribution from CFD (St); c) thermogram with indication of the rows used for spanwise averaging $(\hookleftarrow \longrightarrow)$ of the undisturbed and disturbed (turbulent) flows; d) oil flow visualization; e) chordwise velocity contours from CFD

Eventually, the turbulent separated flow reattaches at 95\%-chord (third inflexion point in $\tilde{T}$ ) before separation occurs again up-stream of the Trailing Edge (TE). The agreement with the oil-flow visualizations is excellent.

Such agreement was also reported for an SD7037 airfoil at low Reynolds number in [23] and a symmetric NACA 16-series in [24]. However, it should be noted that the possible occurrence of reattachment cannot be deduced from the thermograms or temperature profiles alone as is evidenced from the comparisons of Figs. 4(b) and (c) and 5(b) and (c).

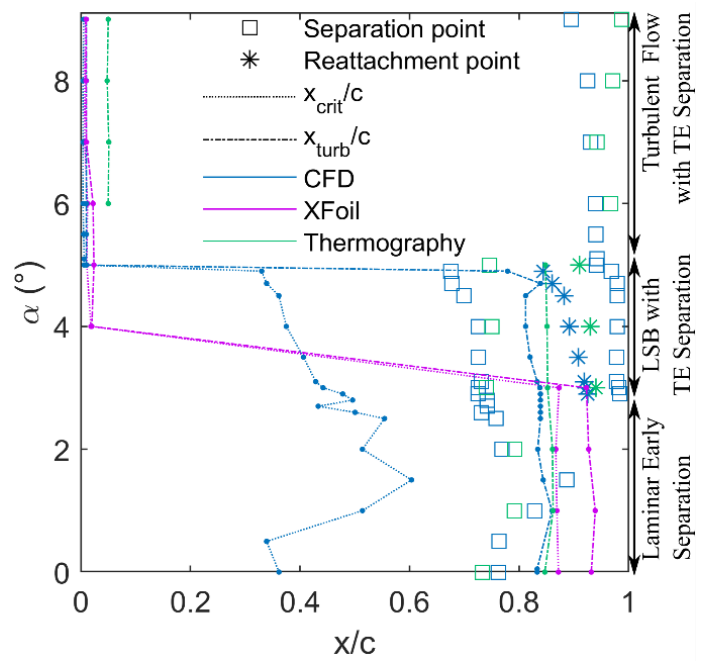

Fig. 7. Separation, reattachment, transition, and critical location $(\mathrm{x} / \mathrm{c})$ versus angle of attack $\alpha$ for the suction side of the NACA16009 airfoil $\left(C_{l d}=0.3675\right)$

At $9^{\circ}$ angle-of-attack as shown in Figs. 6, the flow over the airfoil is entirely turbulent and differences between the disturbed and undisturbed flow vanish. The comparison of the gradient with Figs. 5 stresses the need for a witness flow since inferring the laminar or turbulent behavior of the flow from the gradient of the undisturbed flow alone only increases the risk for erroneous observations. The complex flow around the leading edge, resulting in leading-edge separation and consecutive turbulent early reattachment, as witnessed by the pressure distribution, results in a change in the surface temperature distribution at 5\%-chord. The turbulent flow separates again at $98 \%$-chord leading to another change in surface temperature gradient. Good agreement is found between IR-thermography and visualizations for the location of the separation point (as in [23]) which is predicted $8 \%$-chord upstream by the CFD. The flow patterns observed in the previous results are summarized in Fig. 7 showing the dependency on the angle of attack of the separation/reattachment points together with the critical point and transition location. On top of the results deduced from the IR-thermography and the CFD, the critical and transition point found using XFOIL [48] are shown. The agreement on the transition location between CFD and IR-thermography is of the order of 5\%-chord as is also reported in [14], [23], [46], [49] for other airfoilMach combinations. This agreement is met even in the presence of a laminar separation bubble. The discrepancies with XFOIL are of the order of $10 \%$-chord as reported in [46]. XFOIL does not predict the occurrence of a LSB between $3^{\circ}$ and $5^{\circ}$ angle-of-attack.

The overall agreement pertaining to the separation/reattachment points is of the order of 5\%chord. The distinct flow patterns are in relation with the observed lift and drag coefficients shown in Fig. 8. The figure compares the CFD results with the measured coefficients, those collated in [4] in the incompressible limit, and those obtained with XFOIL [48] (with $N_{\text {crit }}=10$ corresponding to a clean wind tunnel). 


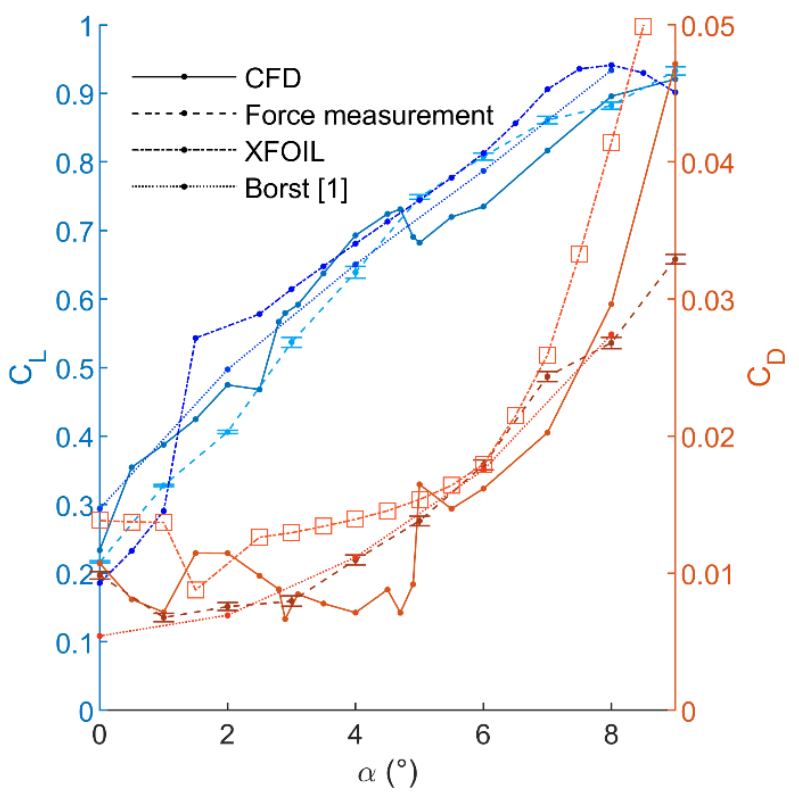

Fig. 8. Lift and drag coefficients for the cambered NACA16009 airfoil $\left(C_{l d}=0.3675\right)$

The measured forces are corrected for solid and wake blockage according to [50]. The qualitative behavior of the results is similar although large discrepancies exist. Both the CFD and the force measurements bear the trace of the distinct flow patterns identified in the previous paragraphs. Particularly, the LSB $\left(3^{\circ}\right.$ and $5^{\circ}$ angle-ofattack) comes with relatively low drag and high lift when compared to the surrounding angles. The installation of the fully turbulent flow above $5^{\circ}$ angle-of-attack comes with a sharp increase in drag and a small drop in lift, thereby substantiating the comments on high angle-ofattack performance of the NACA 16-009 in [4], although the cause of this behavior is not that the flow is fully separated but that it is fully turbulent.

\section{Conclusion}

A cambered NACA16-series airfoil (NACA 16-409 with $C_{l d}=0.3675$ ) has been investigated at low Mach and Reynolds numbers as would typically be encountered during take-off/landing and initial climb when used in a propeller blade. The results from infrared thermography, force measurements, oil flow visualizations, transitional SST k- $\omega$ \& $\gamma$ RANS simulations, and XFOIL are in overall good agreement and depict three distinct flow patterns:

1. From $0^{\circ}$ to less than $3^{\circ}$ angle-of-attack: attached laminar flow that separates early $(75 \%$ - to $80 \%$ chord), the separated shear layer becomes turbulent but does not reattach;

2. From $3^{\circ}$ to less than $5^{\circ}$ angle-of-attack: a laminar separation bubble extends from about $73 \%$ - to $93 \%$ chord, the separated shear layer is transitional at $84 \%$-chord, the reattached turbulent flow separates again $2 \%$ up-stream of the trailing edge;

3. Above $5^{\circ}$ to $9^{\circ}$ angle-of-attack: attached turbulent flow but for the existence of a leading edge separation bubble, the turbulent boundary layer separates around 90\%-chord.

In light of these patterns, the reported high angle-ofattack efficiency loss of the NACA 16-series family can be better understood. Next, we believe the present investigations also substantiate the following remarks:

- The use of infrared thermography, and in particular the analysis of low pass filtered temperature profiles for the presence of inflexion points, provides interesting perspectives. However, the technique cannot discriminate for late reattachment and the use of a turbulent witness-flow is mandatory;

- The local correlation-based transition model is able to predict laminar separation bubbles as well as simple separation phenomena with the same accuracy as eddy-viscosity-based phenomenological transition models;

- Although XFOIL is a great tool for the prediction of lift and drag characteristics of airfoils, the reality of the flow behind these characteristics is quite different from the predicted behavior in particular for the NACA16-series and its sharp leading edge. This might explain part of the discrepancies observed in propeller applications when using XFOIL for blade element analysis.

\section{Acknowledgements}

The authors wish to acknowledge M. Carbonaro of the von Karman Institute for Fluid Dynamics for the courtesy of the oils and pigments mixture used for visualization; D. Helsen and B. Bottin of the Institut Supérieur Industriel de Bruxelles for the collaborative design and manufacture of the aerodynamic balance; and A. de la Filolie from the Ecole de l'Air de Salon- deProvence for the force measurements.

\section{References}

[1] Borst, H.: Summary of propeller design procedure and data. volume $i$ : aerodynamic design and installation. Technical Report 73-34A, Army Air Mobility Research and Development Laboratory, Rosemont (USA) (1973)

[2] Taverna, F.: Advanced airfoil design for general aviation propellers. Journal of Aircraft 21(9), 649-657 (1984)

[3] Black, D., Menthe, R., Wainauski, H.: Aerodynamic design and performance testing of an advanced $30^{\circ}$ swept, eight bladed propeller at Mach numbers from 0,2 to 0,85. Contractor Report CR 3047, National Aeronautics and Space Administration, NASA Lewis research center (USA) (1978)

[4] Gur, O., Rosen, A.: Optimization of propeller based propulsion system. In: 49 th AIAA/ASME/ASCE/AHS/ASC Structures, Structural Dynamics, and Materials Conference, vol. 46, pp. 95106 (2009)

[5] Marinus, B.: Multidisciplinary optimization of aircraft propeller blades. Phd, Centrale Lyon - Royal Military Academy - von Karman Institute, Brussels (2011) (available at www.theses.fr/2011ECDL0033)

[6] Tan, C.H., Voo, K.S., Siauw, W.L., Alderton, J., Boudjir, A., Mendona, F.: CFD analysis of the aerodynamics and aeroacoustics of the NASA SR-2 propeller. In: ASME Turbo Expo 2014: Turbine Technical Conference and Exposition, GT2014- 
26779. Düsseldorf (Germany) (2014).

[7] Giannakakis, P., Laskaridis, P., Nikolaidis, T., Kalfas, A.I.: Toward a scalable propeller performance map. Journal of Propulsion and Power 31(4), 1073-1082 (2015). doi: 10.2514/1.B35498

[8] Morgado, J.; Silvestre, M., Páscoa, J.: Validation of new formulations for propeller analysis, Journal of Propulsion and Power 31(1), 467-477 (2015). doi: 10.2514/1.B35240

[9] Villar, G.; Lindblad, D., Andersson, N.: Effect of airfoil parametrization on the optimization of counter rotating open rotors. In: AIAA Scitech 2019 Forum, AIAA 2019-0698. San Diego (USA) (2019). doi: $10.2514 / 6.2019-0698$

[10] Abbott, I., von Doenhoff, A., Stivers Jr, L.: Summary of airfoil data. Report R-824, NACA, NACA-Langley aeronautical laboratory (USA) (1945)

[11] Lindsey, W., Stevenson, D., Daley, B.: Aerodynamic characteristics of 24 NACA 16-series airfoils at Mach numbers between 0.3 and 0.8. Tech. Rep. TN 1546, NACA, Langley (1948)

[12] Cleary, H.E.: The effects of Reynolds number on the application of NACA 16-series airfoil characteristics to propeller design. Tech. Rep. NACA TN-2591, NACA (1952)

[13] Schlichting, H., Boundary-Layer Theory (7th edition, McGrawHill, 1979).

[14] Crivellini, A., DAlessandro, V.: Spalart-Allmaras model apparent transition and RANS simulations of laminar separation bubbles on airfoils. International Journal of Heat and Fluid Flow 47, 70-83 (2014). doi: 10.1016/j.ijheatfluidflow.2014.03.002

[15] Ghorbanishohrat, F., Johnson, D.: Evaluating airfoil behaviour such as laminar separation bubbles with visualization and IRthermography methods. Institute of Physics Publishing (2018). doi: 10.1088/1742-6596/1037/5/052037

[16] Mertens, C., Wolf, C., Gardner, A., Schrijer, F., Van Oudheusden, B.: Advanced infrared thermography data analysis for unsteady boundary layer transition detection. Measurement Science and Technology 31(1), id.015301 (2020). doi: 10.1088/1361-6501/ab3ae2

[17] Mertens, C., Wolf, C., Gardner, A.: Unsteady Boundary Layer Transition Detection with Local Infrared Thermography. Notes on Numerical Fluid Mechanics and Multidisciplinary Design 142, 382-391 (2020). doi: 10.1007/978-3-030-25253-3_37

[18] Wolf, C., Mertens, C., Gardner, A., Dollinger, C., Fischer, A.: Optimization of differential infrared thermography for unsteady boundary layer transition measurement. Experiments in Fluids 60, 19 (2019). doi: $10.1007 / \mathrm{s} 00348-018-2667-0$

[19] Dollinger, C., Balaresque, N., Gaudern, N., Gleichauf, D., Sorg, M., Fischer, A.: IR thermographic flow visualization for the quantification of boundary layer flow disturbances due to the leading edge condition. Renewable Energy 138, 709-721 (2019). doi: 10.1016/j.renene.2019.01.116

[20] Reichstein, T., Schaffarczyk, A., Dollinger, C., Balaresque, N., Schülein, E., Jauch, C., Fischer, A.: Investigation of laminarturbulent transition on a rotating wind-turbine blade of multimegawatt class with thermography and microphone array. Energies 12(11), 2102 (2019). doi: $10.3390 /$ en 12112102

[21] Gardner, A., Wolf, C., Raffel, M.: Review of measurement techniques for unsteady helicopter rotor flows. Progress in Aerospace Sciences 111, 100566 (2019). doi: 10.1016/j.paerosci.2019.100566

[22] Ye, Q., Avallone, F., Ragni, D., Choudhari, M., Casalino, D: Boundary layer transition induced by distributed roughness array. In: 11th International Symposium on Turbulence and Shear Flow Phenomena, TSFP 2019. Southampton (United Kingdom) (2019)

[23] Ghorbanishohrat, F., Johnson, D. A.: Evaluating airfoil behaviour such as laminar separation bubbles with visualization and IR thermography methods. In: 7th Conference on Science of Making Torque from Wind, Journal of Physics Conference Series 1037, UNSP 052037, Milan (Italy) (2018). doi. 10.1088/1742-6596/1037/5/052037

[24] Jelinek, T.: Experimental Investigation of the Boundary Layer Transition on a Laminar Airfoil Using Infrared Thermography. In: 12th International Conference on Experimental Fluid Mechanics, EPJ Web of Conferences 180, UNSP 02040, Mikulov (Czech Republic) (2018). doi: 10.1051/epjconf/201818002040

[25] von Hoesslin, S., Stadlbauer, M., Gruendmayer, J., Kähler, C.J.: Temperature decline thermography for laminar-turbulent transition detection in aerodynamics. Experiments in Fluids 58(9), 129 (2017). doi: 10.1007/s00348-017-2411-1

[26] Gardner, A., Eder, C., Wolf, C., Raffel, M.: Analysis of differential infrared thermography for boundary layer transition detection, Experiments in Fluids 58(9), 122 (2017). doi: 10.1007/s00348-017-2405-z

[27] Raffel, M., Merz, C., Schwermer, T., Richter, K.: Differential infrared thermography for boundary layer transition detection on pitching rotor blade models. Experiments in Fluids 56(2) (2015). doi: 10.1007/s00348-015-1905-y.

[28] Simon, B., Filius, A., Tropea, C., Grundmann, S.: IR thermography for dynamic detection of laminar-turbulent transition. Experiments in Fluids 57(5), 1-12 (2016) doi: 10.1007/s00348-016-2178-9

[29] Gardner, A., Eder, C., Wolf, C., Raffel, M.: Analysis of differential infrared thermography for boundary layer transition detection. Experiments in Fluids 58(9) (2017). doi: 10.1007/s00348-017-2405-z

[30] Joseph, L., Borgoltz, A., Devenport, W.: Infrared thermography for detection of laminar-turbulent transition in low-speed wind tunnel testing. Experiments in Fluids 57(5) (2016). doi: 10.1007/s00348-016-2162-4

[31] Szewczyk, M., Smusz, R., De Groot, K., Meyer, J., KucabaPietal, A., Rzucidlo, P.: In-flight investigations of the unsteady behaviour of the boundary layer with infrared thermography. Measurement Science and Technology 28(4) (2017). doi: 10.1088/1361-6501/aa529c

[32] Hue, D., Vermeersch, O., Bailly, D., Brunet, V., Forte, M: Experimental and Numerical Methods for Transition and Drag Predictions of Laminar Airfoils. AIAA Journal 53(9), 2694-2712 (2015) doi: $10.2514 / 1 . J 053788$

[33] Raffel, M., Merz, C.: Differential infrared thermography for unsteady boundary-layer transition measurements. AIAA Journal 52(9), 2090-2093 (2014) doi: 10.2514/1.J053235

[34] Carlomagno, G., Cardone, G.: Infrared thermography for convective heat transfer measurements. Experiments in Fluids 49, 1187-1218 (2010). doi: 10.1007/s00348-010-0912-2

[35] Ricci, R., Montelpare, S., A quantitative IR thermographic method to study the laminar separation bubble phenomenon. International Journal of Thermal Sciences 44(8), 709-719 (2005). doi: 10.1016/j.ijthermalsci.2005.02.013

[36] Gartenberg, E. \& Oberts A.S., J.: Twenty-five years of aerodynamic research with infrared imaging. Journal of Aircraft 29(2), 161-171 (1992). doi: $10.2514 / 3.46140$

[37] TC 180/SC 4 Systems - Thermal performance, reliability and durability: Solar heating - domestic water heating systems - part 1: Performance rating procedure using indoor test methods. Tech. Rep. ISO 9459-1:1993, International Organization for Standardization (1993)

[38] Bosschaerts, W., Suy, O., Marinus, B.: Testing renewable energy equipment: Space heating and warm sanitarian water production Setup of a test facility. European journal of mechanical and environmental engineering 48(2), 109-119 (2003)

[39] Richter, K., Schülein, E.: Boundary-layer transition measurements on hovering helicopter rotors by infrared thermography. Experiments in Fluids 55(1755), 1-13 (2014). doi: $10.1007 / \mathrm{s} 00348-014-1755-\mathrm{z}$

[40] Krynytzky, A., Ewald, B.: Conventional wall corrections for closed and open test sections, pp. 2-1 - 2-66. AGARD-AG-336 (1998) 
[41] Celik, I., Ghia, U., Roache, P., Freitas, C., Coleman, H., Raad, P.: Procedure for estimation and reporting of uncertainty due to discretization in CFD applications. Journal of Fluids Engineering 130(7), 1-4 (2008)

[42] Reynolds, R., Sammonds, R., Walker, J.: Investigation of singleand dual-rotation propellers at positive and negative thrust, and in combination with an NACA 1-series D-type cowling at Mach numbers up to 0,84. Technical Report TR-1336, NACA, NACAAmes aeronautical laboratory (USA) (1957)

[43] Menter, F.R.: Two-equation eddy-viscosity turbulence models for engineering applications. AIAA Journal 32(8), 1598-1605 (1994). doi: $10.2514 / 3.12149$

[44] Menter, F.R., Langtry, R.B., Likki, S.R., Suzen, Y.B., Huang, P.G., Volker., S.: A correlation-based transition model using local variables: Part i model formulation. In: Volume 4: Turbo Expo 2004, ASME-GT2004-53452 (2004). doi: $10.1115 / G T 2004-53452$

[45] Langtry, R., Menter, F.: Transition modeling for general CFD applications in aeronautics. In: 43rd AIAA Aerospace Sciences Meeting and Exhibit, AIAA 2005-522. Reno (USA) (2005). doi: $10.2514 / 6.2005-522$

[46] Langtry, R. B., Menter, F.R.: Correlation-based transition modeling for unstructured parallelized computational fluid dynamics codes. AIAA Journal 47(12), 28942906 (2009). doi: $10.2514 / 1.42362$

[47] Abu-Ghannam, B.J., Shaw, R.: Natural transition of boundary layers - the effects of turbulence, pressure gradient, and flow history. Journal of Mechanical Engineering Science 22(5), 213228 (1980). doi: 10.1243/jmes_jour_1980_022_043_02

[48] Drela, M., Giles, M.: Viscous-inviscid analysis of transonic and low Reynolds number airfoils. AIAA Journal 25(10), 1347-1355 (1987).

[49] Wang, G., Mian, H.H., Ye, Z.Y., Lee, J.D.: Numerical study of transitional flow around NLR-7301 airfoil using correlation-based transition model. Journal of Aircraft 51(1), 342-349 (2014). doi: 10.2514/1.C032211

[50] Barlow, Jewel B., William H. Rae, Alan Pope, Low-Speed Wind Tunnel Testing (3rd edition, Wiley, 1999).

\section{Authors' information}

Royal Military Academy, Department of Mechanical Engineering, Brussels B-1000, Belgium.

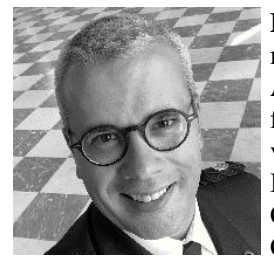

Benoît G. Marinus earned a M.A.Sc. degree in mechanical engineering at the Royal Military Academy of Belgium (Brussels, Belgium) and fruitfully attended the Diploma Course at the von Karman Institute for Fluid Dynamics in Belgium (Rhode-Saint-Genèse, Belgium). Consecutively, he earned a $\mathrm{PhD}$ degree from Centrale Lyon (Lyon, France), the Royal Military Academy, and the von Karman Institute in 2011. His major fields of interest concern external aerodynamics and in particular propeller aerodynamics and aeroacoustics, propeller-wing interaction and propeller aircraft design. Major Marinus holds a position of Associate Professor at the Royal Military Academy of Belgium and Guest Professor at the Vrije Universiteit Brussel, and at Universiteit Gent. He is active in the NATO Science and Technology Organisation panel on Applied Vehicle Technology.

E-mail: benoit.marinus@rma.ac.be

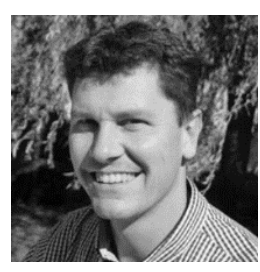

J. Vercauteren is teaching assistant and pilot. He holds a M.A.Sc. degree from the Royal Military Academy. His research expertise is built around measurements in low-speed flows.
R. Vandenberghe holds a M.A.Sc. degree from the Royal Military Academy. He contributed to this research with his master's thesis using infrared thermography and hot-wire measurements.

J. Smeulders holds a M.Sc. degree from the Royal Military Academy. She contributed to this research with her master's thesis on visualization techniques. 